\title{
Warning: soil erosion and land degradation caused by productive and constructive engineering during construction period.
}

\author{
Yulei Ma ${ }^{1}$, Shubing $\mathrm{Dai}^{1}$, and ZhiTao $\mathrm{Ma}^{2}$ \\ ${ }^{1}$ Dalian University of Technology \\ ${ }^{2}$ Ningxia Chengzhixin Electric Power Construction Consulting company limited
}

August 17, 2020

\begin{abstract}
Serious environmental issues, especially soil erosion and land degradation, caused by productive and constructive engineering in China have not gained due attention as those issues caused by natural factors, such as rainfall, wind or Freeze-thaw. Four field investigations together with a statistical study have been carried out in China to analyze environmental problems caused by clean energy projects, i.e. photovoltaic power and wind power projects, that are considered to have huge potential to replace traditional energy. The investigations show that these projects brought problems of land degradation, threatening safety and ecological degradation. Statistical analysis indicates that the number of productive and constructive engineering causing soil erosion was increasing year by year and reached $42.67 \times 104 \mathrm{~km} 2$ from 2003 to 2018, the corresponding scope of soil erosion prevention and control responsibility was $23.22 \times 104 \mathrm{~km} 2$. Finally, seven policy suggestions to deal with these environmental issues are proposed, which can provide reference and guidance for the future clean energy projects and other construction projects in China or other countries. We hope that a thorough understanding of the unsustainable development that leads to the deterioration of the environment in current cases will enhance the awareness of environmental protection and contribute to the implementation of policies that will promote sustainable development.
\end{abstract}

Warning: soil erosion and land degradation caused by productive and constructive engineering during construction period

Yulei $\mathrm{Ma}^{1}{ }^{+}$, Shubing $\mathrm{Dai}^{1}{ }^{+}, *$, Zhitao $\mathrm{Ma}^{2}$

${ }^{1}$ School of Hydraulic Engineering, Dalian University of Technology, Dalian 116024, China

${ }^{2}$ Ningxia Chengzhixin Electric Power Construction Consulting company limited, Yinchuan 750000, China

* Correspondence Dr. Shubing Dai, School of School of Hydraulic Engineering Dalian University of Technology 116024, Liaoning, China. Email address:daishubing1990@163.com

+ These authors contributed to the work equally and should be regarded as co-first authors

Abstract:Serious environmental issues, especially soil erosion and land degradation, caused by productive and constructive engineering in China have not gained due attention as those issues caused by natural factors, such as rainfall, wind or Freeze-thaw. Four field investigations together with a statistical study have been carried out in China to analyze environmental problems caused by clean energy projects, i.e. photovoltaic power and wind power projects, that are considered to have huge potential to replace traditional energy. The investigations show that these projects brought problems of land degradation, threatening the safety and ecological degradation. Statistical analysis indicates that the number of productive and constructive engineering causing soil erosion was increasing year by year and reached $42.67 \times 10^{4} \mathrm{~km}^{2}$ from 2003 to 2018 , the corresponding scope of soil erosion prevention and control responsibility was $23.22 \times 10^{4} \mathrm{~km}^{2}$. Finally, seven policy suggestions to deal with these environmental issues are proposed, which can provide reference 
and guidance for the future clean energy projects and other construction projects in China or other countries. We hope that a thorough understanding of the unsustainable development that leads to the deterioration of the environment in current cases will enhance the awareness of environmental protection and contribute to the implementation of policies that will promote sustainable development.

KEYWORDS: land degradation, soil erosion, ecological degradation, sustainable development, clean energy project, policy suggestions

\section{1 | INTRODUCTION}

China has long been suffering from serious soil erosion. The environmental problems caused by soil erosion, i.e. land degradation and the loss of land resources, have become more serious, which have seriously threatened food security, biodiversity, water resources safety, and human living environment in China (Li \& Fang, 2016). Soil erosion caused by natural factors is widely distributed on all the earth surfaces, so numerous studies focus on the soil erosion problems caused by natural factors, e.g. rainfall (Xu et al., 2020), topography slope (Li et al., 2020), wind (Wang \& shao, 2013), vegetation cover (Zhou, 2008), freeze-thaw (Wu et al., 2018).

However, as everyone knows, soil erosion is strongly influenced by not only natural factors but also unreasonable human activities. It is estimated that nearly $60 \%$ of present soil erosions are induced by human activity (Yang et al., 2003). Currently, China faces economic development, numerous productive and constructive engineerings as one kind of severe human activity are being conducted. Jiang (2007) found that the total number of productive and constructive engineering was $7.68 \times 10^{4}$, the total area was $552.8 \times 10^{4} \mathrm{hm}^{2}$ in China from 2001 to 2005. However, productive and constructive engineering involves extensive land disturbance, which results in the removal of vegetation, mass wasting along the cut slopes, runoff over bare areas formed by excavation, unconsolidated deposition, and reshaping of the topography (Li et al., 2014). Such activities directly cause soil erosion and land degradation. For example, Jiang (2007) pointed out that the total amount of abandoned soil and slag was about $92.1 \times 10^{8} \mathrm{t}$, and the total amount of soil erosion was $9.5 \times 10^{8}$ t in China from 2001 to 2005. Also, Zhang et al. (2006) estimated that the area of land degradation caused by productive and constructive engineering accounted for $66 \%$ of the total area of land degradation and about $60 \%$ of land occupied by productive and constructive engineering was farmland. The loss of land resources caused by that farmland is converted into construction land in China indirectly results in that a large amount of ecological land is reclaimed as farmland. So, productive and constructive engineering has brought serious land degradation, loss of land resources and loss of ecological land along with soil erosion. However, these environmental issues caused by productive and constructive engineering in China have not gained enough attention. Only a few studies of soil erosion caused by mining (Sinha et al., 2017) and road (Dong et al., 2012) projects are available. Therefore, this article focuses on the problem of soil erosion and related environmental issues caused by productive and constructive engineering, and specifically selects clean energy projects, such as photovoltaics and wind energy, across China as case studies. Because clean energy emits fewer greenhouse gases and is more environmentally friendly than traditional energy projects such as petroleum, natural gas, and coal, clean energy will be the trend of future energy supply. At the same time, it also causes many man-made environmental problems like other construction projects, which can provide a reference for the construction projects of other industries.

Here, the authors have conducted field investigations and statistical analysis of clean energy projects in China for years, which have been used to understand the reasons causing these environmental issues. In turn, some comprehensive policy suggestions are proposed to enhance the awareness of protecting environments in the process of constructive engineering and to control these issues. And, the conclusions and policy recommendations of this article will provide reference and guidance for clean energy projects construction in the future and even other large-scale productive and constructive projects in China or other countries.

\section{2 | MATERIAL AND METHODS}

Figure 1a shows the distribution of land wind power projects in 2019, indicating that a large number of projects are constructing in China, with 313 projects nationwide. It is distributed throughout the country, mainly in central and eastern China. As shown in Figure 1b, 4 typical clean energy projects from northwest 
to north China are selected as study cases. The study area is located in the eastern longitude 105 deg 09 '-116 deg 16 ' and northern latitude $36 \operatorname{deg} 06$ ' -38 deg 31 '. The photovoltaic power project is located in Zhongning County, Ningxia Province, which is a type II region (Shen, 2014) with abundant solar energy in China. It is a typical example with the most abundant solar energy resources, low rainfall, and low vegetation cover in the northwest ecological embrittlement region of China. Its annual sunshine hours are $3000^{\sim} 3200$ hours and the radiation amount is $586^{\sim} 670 \times 10^{4} \mathrm{~kJ} / \mathrm{cm}^{2 *}$ a. Three wind farms are located in the Haiyuan County, Ningxia Province, Yu County, Shanxi Province, and Gucheng County, Hebei Province, involving the loess hilly-gully region in western China, the mountainous region in central China and the plains region in eastern China. Three wind farms are built on the loess hilltop, the top of the earth and rock mountain, and the open plain respectively, which almost react all kinds of typical situations to be faced in the construction of land wind farms. Due to technical reasons, some of the wind farms must be built on the top of the mountain or the hill to capture maximum wind energy resources, and therefore roads and land leveling must be completed before the construction of wind farms. These activities will cause interference on the surrounding areas widely, serious environmental problems will appear if the soil and water conservation measures have not been taken. Other wind farms are built in the open plains and these plains are fertile farmlands, so the construction of wind farms will cause relatively big disturbance to the farmland. From 2015 to 2019, we found some soil erosion and related environmental problems in the supervision process of a large number of principal parts of the clean energy projects, so we selected the above several representative construction projects for in-depth analysis.

\section{3 | RESULT}

\subsection{Land degradation}

The land can undertake a variety of functions such as offering economic benefits, maintaining social stability, ensuring food security, and protecting ecological environment (Xiao et al., 2018). However, productive and constructive engineering always causes land destruction, which is mainly manifested in the excavation, and cover and occupation of the land. In the process of productive and constructive engineering, serious soil erosion always occurs in the construction area due to a lack of awareness of soil erosion protection and the weakness of protection measures. Especially in the ecological environment fragile areas, productive and constructive projects cause serious soil erosion, even soil desertification. As shown in Figures 2 and 3, soil desertification has been caused by the photovoltaic power generation project located in Zhongning County, Loess Plateau, Ningxia Province. This area is one of the ecologically fragile areas in China because the area is characterized by the low vegetation cover and highly erodible loess soil, and it is significantly impacted by climate change and human activity. The land-use type in the project construction area is grassland before the photovoltaic power project is constructed. However, land leveling of project construction area destroyed surface vegetation, resulting in that soil lost fine particle (silt and clay particle) and gradually became sandy, and eventually forming mobile dunes after the construction of the project (Figure 3 ). Zhang et al. (2006) found that desertification of the grassland and cultivated land were the most serious for all kinds of desertification of land, accounting for about $79.2 \%$ of the total. Besides, water erosion also occurred in the process of construction (Figure 4). If the constructive area is not treated promptly after excavation, rainfall directly causes water erosion and soil nutrients loss of exposed surface. The soil erosion and land desertification mentioned above are the most typical forms of land degradation. The land cover and occupation also occurred in productive and constructive projects (Figure 5). Cover and occupation of farmland not only narrow the area of farmland but also influence the growth and yield of the crop. Rapid industrialization has encroached a huge quantity of agricultural land and has caused a continuous reduction of farmland by an unprecedented degree, in which $60 \%$ of non-agricultural occupied land originates from farmland (Zhang et al., 2006; Liu et al., 2010). Although non-agricultural land use seems not to be land degradation, the destructive land-use change could lead to the loss of farmland. Also, non-agricultural land use may inevitably indirectly increase the input of chemical energy per unit area to guarantee food security due to the loss of farmland, ultimately resulting in land degradation and environmental pollution.

\subsection{Threatening safety}


The constructive and productive engineering requires the excavation and backfill of earth and stone, which generates abandoned earth and slag, disturbs the surface vegetation, triggers water and soil loss, and brings a certain impact on the local ecological environment. Because soil and water conservation projects are ancillary projects, its construction quality being good or bad will not have a subversive effect on the product profit. Therefore, some design units and construction units have the same idea that the principal part of the project can spend as much as possible, and the water and soil conservation project should spend as little as possible. The low investment cost of soil and water conservation led to the low standards and quality of engineering, in turn, threatening the safety of the principal parts of the projects. As shown in Figure 3c, photovoltaic panels are vulnerable to damage when the wind blows away the soil around their supports. On the other hand, during the construction process, due to a lack of awareness of soil protection, large-scale site leveling in the construction area destroyed the vegetation, providing a favorable environment for soil erosion. After the completion of construction, no timely soil and water conservation measures - vegetation restoration - resulted in serious soil erosion and threatened the safety of the principal part of the project. For productive and constructive engineering, the production road is extremely important, which is built to ensure that vehicles, personnel, and materials can be timely transported to the construction site. As shown in Figure 4a, although the production road was paved with sand and drainage ditches were designed on both sides of the road, it was destroyed by water erosion during the construction of wind power projects due to low-quality protection. No protection measures had been implemented for the slope after which was cut very steeply, resulting in serious water erosion and destroying the drainage ditches beneath the slope (Figure 4b). Besides, due to neglect of soil and water conservation and lack of awareness of soil protection, the foundation soil was seriously eroded and lost, thus undermining the stability of the foundation and threatening the safety of the transmission tower (Figure 4c), the wind-driven generator and transformer room (Figure 4d). Especially as soil erosion progresses, it will cause the electrical tower to collapse and wire to break or even to fire. Besides, neglect of soil and water conservation in the construction areas may also cause casualties and tremendous damage. Especially the excavation and backfill in the process of productive and constructive projects may cause emergent and dangerous events, such as collapse, landslide, and debris flow. For example, a catastrophic landslide occurred at Hongao dumpsite on Dec 20, 2015, in Shenzhen, Guangdong, Southeast China. The landslide caused 69 causalities with 8 missings, damaged 33 buildings and caused near 800 million RMB economic loss (Xu et al., 2016), related soil and water conservation engineers were arrested. For the safe operation of the principal part of the project, the implementation of soil and water conservation projects is essential for constructive and productive engineering.

\subsection{Ecological degradation}

The productive and constructive engineering may interfere with native ecosystems through the excavation, cover and occupation of land, destruction of vegetation, and consumption of energy and resource. Although wind and solar energy are clean energy sources, those have also caused inescapable environmental issues in practical applications. The construction of clean energy destroyed forests (Figure 6) and grasslands (Figure 2 and Figure 3b), and reshaped the landforms (Figure 3a), resulting in a lack of nutrients suitable for plant growth on the new surface, and thus leading to vegetation recovery is difficult. Once the land has been desertification (Figure 3), the treatment of land desertification needs to take more time and money to restore vegetation in mobile dunes and stabilize sand fields. Besides, the construction of clean energy also caused environmental pollution, such as photovoltaic projects. Wastewater and exhaust gas were generated during the production of monocrystalline silicon which is the main material of solar cell panels. Besides, once the solar cell is retired, itself becomes untreatable waste (Tammaro et al., 2016). Moreover, if endless solar panels are planted as crops in the fields, the right to enjoy the sunshine of plants and land is deprived, which may lead to the negative impacts on biodiversity and ecosystem functions. For example, Xu et al. (2019) reported that to avoid the negative impact of the photovoltaic project on the land, the so-called "ecological photovoltaic" was implemented by planting vegetables and raising rabbits in the remaining space of photovoltaic farm station, which ultimately failed due to the lack of sunlight. Besides, wind power as another clean energy also brought negative effects on the environment. It was reported that the noise, electromagnetic radiation, and moving shadows generated by the wind power generator near the Trionyx 
Sinensis farms affected the reproduction and growth of the Trionyx Sinensis, resulting in a loss of RMB 1.63 million (Bai, 2019).

\section{4 | DISCUSSION}

\subsection{Urgency and confliction}

China is undergoing rapid economic growth and urbanization. The projects, such as construction and development of cities and towns, highway and railway, resource exploitation, are advancing at unprecedented scale and speed. As shown in Figure 7, the number of productive and constructive projects involving soil erosion was $42.67 \times 10^{4}$ from 2003 to 2018, the corresponding scope of soil erosion prevention and control responsibility was $23.22 \times 10^{4} \mathrm{~km}^{2}$ (MWRPRC, 2003-2018), almost the same area of the UK $\left(24.3 \times 10^{4} \mathrm{~km}^{2}\right)$. This indicated that the number of productive and constructive projects remained high and even increasing trend, and the corresponding scope was very wide. Accelerated soil erosion accompanied by human irrational activities - land exploitation, deforestation, and the anthropogenic water and soil erosion, is also very serious. The contradiction between development and protection is very prominent.

Also, although the law of soil and water conservation stipulates that the management of soil and water loss caused by the productive and constructive engineering should be strengthened in mountainous, hilly, and wind and sand areas. However, the people living in this mountainous area have to face a conflict between promoting economic growth and protecting the soil and water environment. However, neglecting water and soil conservation during the period of construction caused serious soil erosion (Figure 4) and even land desertification (Figure 3). Hence, if the soil erosion caused by the productive and constructive engineering is not controlled, the increasingly serious water and soil loss will not only restrict the development of economy and society but also pose a threat to the country's ecological security.

\subsection{Economic loss}

China, the most populous nation, is a developing country and is still overwhelmingly rural, yet aspires for fast modernization of the economy (Smil, 1981). The production and construction activities can bring great economic benefits and value in use for the country, so numerous productive and constructive engineerings are undergoing. However, these projects are causing the overdraft of natural resources and damage to the environment (Du et al., 2017). Also, Cheng et al. (2015) found anthropogenic water and soil losses and huge economic losses caused by productive and constructive projects were more and more serious recently. In 1990, Chinese economic losses caused by soil and water loss totaled RMB 26.4 billion Yuan, such as food loss, nutrition loss, falling crop yields, and cost of Point-of-Use water purification (Jiang, 2007). Ren et al. (1997) estimated that the economic losses caused by water and soil erosion were RMB 49.5 billion Yuan, accounting for $6.5 \%$ of Chinese agricultural output value in the same period. Ministry of Water Resources of PRC, Chinese Academy of Sciences and Chinese Academy of Engineering conducted the science review of soil and water erosion and ecological safety in China, 2006. It was found that the economic loss caused by soil erosion was 188.7 billion Yuan in 2000 - the direct economic loss was RMB 64.26 billion Yuan and indirect economic loss was RMB 124.44 billion Yuan, accounting for $2.1 \%$ of the total GDP of the year (Jiang, 2007). Resource and environmental problems have become a serious problem in the sustainable development of China. Hence, the management of water and soil erosion is, naturally, of critical importance for China. From the perspective of economics, neglecting the cost of natural resources and the environment are the main reasons for these environmental problems. To put it bluntly, low investment and lack of protection awareness caused by low investment are the cruces of soil and water loss. Scientific estimation of investment in soil and water conservation measures becomes the key.

Previously, the degree of soil erosion in all soil and water conservation plans had never been evaluated and controlled hierarchically, resulting in that investment of soil and water conservation projects had not been determined hierarchically according to different severity degree of soil erosion. All projects were carried out following the same investment standard, leading to investments of some projects were too high, and investments of other projects were unable to control soil and water loss. Thus the degree of soil erosion can be classified according to the amount of soil erosion calculated by the universal soil loss equation (USLE) or its 
revised universal soil loss equation (RUSLE) and the corresponding economic loss, because this classification method is quite common and widely used in various fields, for example, the classification of the landslide is mainly in accordance with the amount of the landslides, the economic loss of landslides and the death toll (MLRPRC, 2004). Then, a large number of projects are carefully analyzed and summarized to calculate expenses per unit area required for the projects of different grades, in turn, investments of soil and water conservation measures required for different projects can be calculated. Traditional one-size-fits-all computing investment for all projects based on the same standard should be abandoned because the projects that are built with investment calculated by traditional methods still cause soil erosion at many cases even though the soil and water conservation measures have been done, but it is not enough due to low investment, as shown in Figure 4b. Of course, this is only the first step of soil erosion control in productive and constructive projects, and more experts, scholars, engineers, and managers are needed to carefully summarize numerous projects in different regions to determine more effective and reliable investments per unit area. Besides, previously, all the water and soil conservation plans never calculate economic loss as a quantitative index due to soil erosion, usually just give a predicted amount of soil erosion. Actually, the predicted amount of soil erosion has no direct effect on the investment by the decision-makers, because policymakers are concerned about money more. Until the amount of soil erosion is converted into money, policymakers will have an intuitive understanding of the extent of soil loss. If the economic losses of soil erosion are put into the soil and water conservation plan, project earnings and economic loss will be easy to compare, this will help decision-makers make decisions that help protect the environment by increasing investment or improving awareness of environmental protection and so on.

The economic loss caused by soil erosion can be calculated according to the following components. The economic loss includes direct and indirect economic loss. The direct economic loss includes sediment loss, nutrient loss, water loss, while the indirect economic loss is divided into the damage of water resource and ecological environment, and the decline of productivity and water-holding capacity of land, etc. (Wang et al., 2011). Also, the cost of repairing a damaged ecosystem caused by soil and water loss may be considered as economic loss, such as the costs of soil and water conservation measures. These detailed calculation examples can be found in the literatures (Wang et al., 2011; Lv et al., 2012).

\subsection{Defense scenario}

It is undeniable that clean energy will replace traditional energy in the near future because it can mitigate greenhouse gas emissions and environmental pollution. However, the cost of soil and water conservation for clean energy projects is relatively low, accounting for only 0.4 to $4 \%$ of the total project investment (Jiang, 2007). Besides, many productive and constructive projects in China ignore environmental regulations, because local governments tend to prioritize making money over protecting the environment (Li et al., 2014). So numerous environmental issues have been still caused by clean energy projects which, even though, is considered to cause fewer environmental problems. From a technology perspective, controlling soil and water loss is not difficult in project construction, 5 specific points are shown as the following. First, it is necessary to ensure the protection measures and funds of the ecological environment before productive and constructive engineering can be constructed. Because, generally speaking, construction companies attach great importance to the quality, technology, and management of the principal part of the project, but the soil and water conservation measures have problems of low investment levels, low engineering standards, backward technological means, outdated ideas, and lax management systems (Zhang, 2002). At the same time, soil and water conservation investment needs to be scientifically estimated according to the aforementioned soil erosion classification to ensure enough investment. Second, it is necessary to change the old idea pollute first, clean up later - to truly ensure that soil and water conservation facilities must be designed, constructed, and commissioned simultaneously with the principal part of the project, so that clean energy does not depart from the original intention of decreasing the pollution. For structurally controlled soil and water loss during production and construction activities, comprehensive control that combines structural, vegetative, and managerial measures is advocated, which ensures the ecological and environmental benefits with less investment. As a minimum the following recommendations should be needed during the construction process: during ground excavation works in the construction of projects, soils should be watered to raise the 
moisture content to avoid dust pollution; ground cover and trees on hills and in gullies that are destroyed before infilling should be replanted as soon as possible to prevent soil erosion; irregular configurations of terrain with steep slopes and varying degrees of instability need to be managed to avoid gravity erosion; and farmers who lose farmland should be compensated. Third, soil and water conservation monitoring and the principal part of the development and construction project must be carried out at the same time to ensure the timely implementation of soil and water conservation engineering measures, in turn, to avoid dozens or even hundreds of times restoration costs required for soil erosion treatment if serious soil erosion or even land desertification is caused by that the soil and water conservation engineering measures have not been implemented timely. Soil and water conservation projects for which soil and water conservation monitoring is not carried out promptly shall be strictly handled in accordance with the law. Fourth, as part of the capacity-building efforts in environmental control, an exclusion zone is also needed in an ecologically fragile area, which prevents any human activity from aggravating the environmental disaster. The last but not the least, processes of soil formation proceed very slowly, $1 \mathrm{~cm}$ of soil humus is formed under natural conditions every 300-400 years (Zharikov et al., 2002). However, it is eroded in only one year. Hence, public awareness of soil erosion prevention should be improved, which is considered as an important factor for fundamentally controlling environmental issues caused by productive and constructive engineering.

\section{5 | CONCLUSIONS}

Through field investigations of 4 clean energy projects, it is found that, during the construction process, land degradation, threatening the safety and ecological degradation occurs widely in China. The number of productive and constructive projects involving soil erosion was $42.67 \times 10^{4}$ from 2003 to 2018, correspondingly their scope of soil erosion prevention and control responsibility was $23.22 \times 10^{4} \mathrm{~km}^{2}$, almost the same area of the UK $\left(24.3 \times 10^{4} \mathrm{~km}^{2}\right)$. Confliction between economic development and environmental protection is very strong in China from mountainous regions to urban regions. So, some policy suggestions are proposed as follows:

(1) The degree of soil erosion should be classified according to the amount of soil erosion and the corresponding economic loss to guarantee enough investment for the water and soil conservation projects. (2) The economic loss of soil erosion should be predicted in the soil and water conservation plan to help decisionmakers make decisions that are more environmentally friendly. (3) It is necessary to ensure the protection measures and enough funds of the ecological environment before constructive engineering can be constructed. (4) It is necessary to change the old idea - pollute first, clean up later - to truly ensure that soil and water conservation facilities must be designed, constructed, and commissioned simultaneously with the main project. (5) Soil and water conservation monitoring and the principal part of the project must be carried out at the same time to ensure the timely implementation of soil and water conservation engineering measures.

(6) An exclusion zone is also needed in an ecologically fragile area, which prevents any human activity from aggravating the environmental disaster. (7) Public awareness of soil erosion prevention should be improved, which is considered as an important factor for fundamentally controlling environmental issues caused by productive and constructive engineering.

The ecological and environmental problems caused by the clean energy projects and their causes, as well as the prevention and treatment policy suggestions can provide reference and guidance for the future clean energy projects and other construction projects in China or other countries, to prevent the common occurrence of similar problems in the future development projects.

\section{DATA AVAILABILITY STATEMENT}

All data included in this study are available upon request by contact with the corresponding author.

\section{REFERENCES}

Bai X.Y. (2019). Wind power companies encounter new types of environmental pollution infringement disputes.http://news.bjx.com.cn/html/20190627/989014.shtml.

Cheng, B., Lv, Y., Zhan, Y., Su, D., \& Cao, S. (2015). Constructing China's roads as works of art: 
a case study of "esthetic greenway" construction in the Shennongjia region of China. Land Degradation Development , 26, 324-330.

Dong, J. Z., Zhang, K. L., \& Guo, Z. L. (2012). Runoff and soil erosion from highway construction spoil deposits: A rainfall simulation study. Transportation Research Part D , 17, 8-14.

Du, H., Ge, M., Zhang, W., \& Chen, Y. (2017). The analysis on the accounting methods system of environmental costs focused on the construction phase of construction projects. In: Proceedings of the 20th International Symposium on Advancement of Construction Management and Real Estate. Singapore, pp. 425-435.

Jiang, D.W. (2007). Analysis of benefit and loss of soil and water conservation for construction projects. Beijing: Beijing Forestry University.

Li, P., Zhang, K. D., Wang, J. W., \& Meng, H. (2020). Nondimensional sediment transport capacity of sand soils and its response to parameter in Loess Plateau of China. Hydrological Processes , 34(3), 823-835.

Li, P. Y., Qian, H., \& Wu, J. H., (2014). Environment: accelerate research on land creation. Nature , 510(7503), 29-31.

Li, Z. Y., Fang, \& H. Y. (2016). Impacts of climate change on water erosion: a review. Earth-Science Reviews , 163, 94-117.

Liu, Y., Zhang, Y., \& Guo, L. (2010). Towards realistic assessment of cultivated land quality in an ecologically fragile environment: a satellite imagery-based approach. Applied Geography , 30(2), 271-281.

Lv H. L., Wu C. G., Zhou, Z. X., Teng, M. J., Xiao, W. F., \& Wang P. C. (2012). Estimation on erosioninduced economic loss in Three Gorges Reservoir area. Bulletin of Soil and Water Conservation, 32, 117-125. (in Chinese)

Ministry of Land and Resources of the People's Republic of China (MLRPRC), 2004. Geology and mineral resources industry standard of the People's Republic of China: standard of classification for geological disaster (DZ 0238-2004), (in Chinese)

Ministry of Water Resources of the People's Republic of China (MWRPRC), 2003-2018. Bulletin of soil and water conservation in China.

Ren, Y., Meng, X. T., Bi, \& H. X., (1997). Economic loss estimation of soil and water loss and environmental economic thinking. Research ofSoil and Water Conservation, (8), 48-50.(in Chinese)

Shen, Y. (2014). The spatial distribution of solar energy and the comprehensive potential evaluation of regional exploitation and utilization in China. Lanzhou: Lanzhou University. (in Chinese)

Sinha, N., Deb, D., \& Pathak, K. (2016). Development of a mining landscape and assessment of its soil erosion potential using GIS.Engineering Geology , 216, 1-12.

Smil, V. (1981). Land use and management in the people's republic of China. Environmental Management , 5, 301-311.

Tammaro, M., Salluzzo, A., Rimauro, J., Schiavo, S., \& Manzo, S. (2015). Experimental investigation to evaluate the potential environmental hazards of photovoltaic panels. Journal of Hazardous Materials , 306, 395-405.

Wang, X., Li, Z. B., Li, P., Zhang, L. H. (2011). Economic loss analysis of soil erosion in Dan-Han River watershed of Shaanxi Province.Journal of Northwest AEGF University (Nat. Sci. Ed.) 39, 214-220. (in Chinese)

Wang, Y. Q., \& Shao, M. A. (2013). Spatial variability of soil physical properties in a region of the loess plateau of PR China subject to wind and water erosion. Land Degradation Development, 24, 296-304. 
Wu, Y. Y., Ouyang, W., Hao, Z. C., Lin, C. Y., Liu, H. B., \& Wang, Y. D. (2018). Assessment of soil erosion characteristics in response to temperature and precipitation in a freeze-thaw watershed.Geoderma, $328,56-65$.

Xiao, W., Fu, Y., Wang, T., Lv, X. (2018). Effects of land use transitions due to underground coal mining on ecosystem services in high groundwater table areas: a case study in the Yanzhou coalfield.Land Use Policy , 71, 213-221.

Xu, G. F., Zhang Z. S., Li, Y. J., Yang, F. (2019). Analysis on the current situation of ecological photovoltaic industry in Northwest China. Northwest Hydropower, 1-7. (in Chinese)

Xu, Q., Peng, D. L., Li. W. L., Dong, X. J., Hu, W., Tang, M. G., \& Liu, F. Z. (2016). The catastrophic landfill flowslide at Hongao dumpsite on December 20, 2015 in Shenzhen, China. Natural Hazards and Earth System Sciences, 1-19.

Xu, X. Z., Ma, Y. L., Yang, W. J., Zhang, H. W., Tarolli, P., Jiang, Y. Z., \& Yan, Q. (2020). Qualifying mass failures on loess gully sidewalls using laboratory experimentation.Catena, 187, (in press)

Yang, D., Kanae, S., Oki, T., Koike, T., Musiake, K. (2003). Global potential soil erosion with reference to land use and climate changes.Hydrological Processes , 17, 2913-2928.

Zhang, K. F., Li, X. W., Zhang D. X., Peng, J. F., Chen, J., Yu Z. R. (2006). Spatial-temporal dynamic change of land resource degradation in China. Environmental Science, 27(6), 1244-1251. (in Chinese)

Zhang, Z. L. (2002). Analysis and countermeasures of investment status of soil and water conservation projects. Research of Soil and Water Conservation, (6), 13-14. (in Chinese)

Zharikov, G. A., Varenik, V. I., Borovick, R. V., Dyadischev, N. R. \& Rybalkin, S. P. (2002). Ecologically safe technology for bioremediation of soils polluted by toxic chemical substances. In: NATO advanced research workshop on environmental aspects of converting CW facilities to peaceful purposes and derivative technologies in modeling, medicine and monitoring. Switzerland.

Zhou, P., Luukkanen, O., Tokola, T., \& Nieminen, J. (2008). Effect of vegetation cover on soil erosion in a mountainous watershed.Catena, 75(3), 319-325.

\section{Hosted file}

Figure 1.docx available at https://authorea.com/users/351258/articles/475953-warning-soilerosion-and-land-degradation-caused-by-productive-and-constructive-engineering-duringconstruction-period

\section{Hosted file}

Figure 2.docx available at https://authorea.com/users/351258/articles/475953-warning-soilerosion-and-land-degradation-caused-by-productive-and-constructive-engineering-duringconstruction-period

\section{Hosted file}

Figure3.docx available at https://authorea.com/users/351258/articles/475953-warning-soilerosion-and-land-degradation-caused-by-productive-and-constructive-engineering-duringconstruction-period

\section{Hosted file}

Figure 4.docx available at https://authorea.com/users/351258/articles/475953-warning-soilerosion-and-land-degradation-caused-by-productive-and-constructive-engineering-duringconstruction-period

\section{Hosted file}


Figure 5.docx available at https://authorea.com/users/351258/articles/475953-warning-soilerosion-and-land-degradation-caused-by-productive-and-constructive-engineering-duringconstruction-period

\section{Hosted file}

Figure 6.docx available at https://authorea.com/users/351258/articles/475953-warning-soilerosion-and-land-degradation-caused-by-productive-and-constructive-engineering-duringconstruction-period

\section{Hosted file}

Figure 7.docx available at https://authorea.com/users/351258/articles/475953-warning-soilerosion-and-land-degradation-caused-by-productive-and-constructive-engineering-duringconstruction-period 